УДК 338.26

DOI: $10.18101 / 2304-4446-2019-4-29-36$

\title{
РАЗРАБОТКА СТРАТЕГИИ РАЗВИТИЯ РЕСПУБЛИКИ БУРЯТИЯ 2030: УПУЩЕННЫЕ ВОЗМОЖНОСТИ И ПРОСЧЕТЫ
}

\section{(c) Дондоков Зорикто Бато-Дугарович}

доктор экономических наук, профессор, главный научный сотрудник,

Бурятский научный центр СО РАН

Россия, 670000, г. Улан-Удэ, ул. Сахьяновой, 8;

профессор,

Бурятский государственный университет имени Доржи Банзарова

Россия, 670000, г. Улан-Удэ, ул. Смолина, 24а

E-mail: dzorikto@mail.ru

\section{(c) Ванчикова Елена Николаевна}

доктор экономических наук, профессор,

проректор по экономике и развитию,

Бурятский государственный университет имени Доржи Банзарова

Россия, 670000, г. Улан-Удэ, ул. Смолина, 24а;

главный научный сотрудник,

Бурятский научный центр СО РАН

Россия, 670000, г. Улан-Удэ, ул. Сахьяновой, 8

E-mail: evanch@mail.ru

В статье проведен анализ разработки Стратегии социально-экономического развития Республики Бурятия до 2030 г. Описаны предложения научной общественности органам законодательной и исполнительной власти республики по вопросам подготовки нормативных правовых документов и созданию механизма разработки документов стратегического планирования в Бурятии. Отражены основные положения Совета по стратегическому планированию социально-экономического развития при главе республики. Показана важность публичного оглашения приоритетов, целей и задач социально-экономического развития Бурятии в формате выступления главы республики. Обоснована необходимость организации эффективного взаимодействия между участниками стратегического планирования. Приведено описание предложенного алгоритма разработки документов стратегического планирования. Показана целесообразность привлечения научно-экспертных организаций и создания консорциума по разработке Стратегии. Выявлены просчеты правительства Республики Бурятия в процессе подготовки долгосрочной стратегии развития республики. Описаны ошибки разработчиков проекта стратегии и причины его неутверждения.

Ключевые слова: стратегическое планирование; регион; социально-экономическое развитие; Республика Бурятия; нормативные правовые акты; научные организации; приоритеты долгосрочного развития; экспертные площадки; общественное обсуждение; предложения и рекомендации; проект стратегии.

\section{Для цитирования}

Дондоков З. Б.-Д., Ванчикова Е. Н. Разработка стратегии развития Республики Бурятия 2030: упущенные возможности и просчеты // Вестник Бурятского государственного университета. Экономика и менеджмент. 2019. № 4. С. 29-36. 
С принятием в 2014 г. закона «О стратегическом планировании в Российской Федерации» в России были установлены правовые основы стратегического планирования на уровне страны, субъектов РФ и муниципальных образований, определен механизм обеспечения взаимодействия участников процесса, представлены перечень документов стратегического планирования и порядок мониторинга и контроля их реализации ${ }^{1}$.

Соответствующие законы, нормативные правовые акты разрабатывались и на региональном уровне. В настоящее время накоплен достаточно значительный опыт территориального планирования в субъектах РФ [1]. Вместе с тем при подготовке документов стратегического планирования на региональном уровне выявились значительные проблемы недостаточности методического обеспечения, включая нехватку документов по организации межведомственного взаимодействия и повышению доступности информации [2].

Основным документом стратегического планирования развития субъекта РФ является стратегия социально-экономического развития. В настоящее время практически все субъекты РФ, за исключением г. Москвы и Тульской области, разработали и утвердили соответствующие документы [3]. В большинстве регионов России эти документы стали разрабатываться на период до 2030 г. или до 2035 г. $^{2}$ Лишь в Костромской, Новгородской и Мурманской областях временной горизонт был установлен значительно меньшим - до 2025 г. Между тем стратегия социально-экономического развития Кабардино-Балкарской Республики была разработана на период до 2040 г. ${ }^{3}$ Среди всех региональных стратегий выделяется стратегия социально-экономического развития Республики Саха (Якутия) до 2032 г. с целевым видением до 2050 г. ${ }^{4}$

В 2015 г. началась активная фаза подготовки нормативных правовых документов, обеспечивающих стратегическое планирование в Республике Бурятия. Правительством республики был подготовлен проект закона «О стратегическом планировании в Республике Бурятия».

Сотрудниками Отдела региональных экономических исследований Бурятского научного центра СО РАН (далее - ОРЭИ БНЦ СО РАН) было предложено Народному Хуралу Республики Бурятия предусмотреть в указанном законопроекте:

- утверждение Стратегии социально-экономического развития Республики Бурятия (далее - Стратегия) Народным Хуралом Республики Бурятия;

\footnotetext{
${ }^{1}$ О стратегическом планировании в Российской Федерации: федеральный закон от 28 июня 2014 г. № 172-Ф3.

2 Доработанные проекты стратегий [Электронный pecypc]. URL: http://economy.gov.ru/minec/activity/sections/StrategTerPlanning/komplstplanning/stsubject/str aterupdate/ (дата обращения: 09.09.2019).

3 Об утверждении Стратегии социально-экономического развития КабардиноБалкарской Республики до 2040 года: распоряжение правительства КабардиноБалкарской Республики от 30 апреля 2019 г. № 251-рп.

${ }^{4}$ О Стратегии социально-экономического развития Республики Саха (Якутия) до 2032 года с целевым видением до 2050 года: закон Республики Саха (Якутия) от 19 декабря 2018 г. 2077-3 № 45-VI.
} 
- порядок взаимодействия органов государственной власти с общественными, научными и иными организациями в сфере стратегического планирования, включая общественное обсуждение проектов документов стратегического планирования Республики Бурятия;

- расширение состава участников стратегического планирования путем включения в него дополнительно органов местного самоуправления.

Правительству Республики Бурятия были направлены следующие предложения по разработке Стратегии:

1. В целях обеспечения взаимодействия органов государственной власти Республики Бурятия с научными, общественными и иными организациями в сфере стратегического планирования создать Совет по стратегическому планированию социально-экономического развития при главе Республики Бурятия (далее - Совет) с включением в него по каждому направлению на паритетных началах представителей органов исполнительной и законодательной власти, научных, общественных и бизнес-сообществ.

2. При разработке и корректировке документов стратегического планирования социально-экономического развития Республики Бурятия обеспечить их широкое общественное обсуждение с привлечением научных и экспертных организаций.

3. Организовать проведение научно-практических конференций по вопросам социально-экономического развития Республики Бурятия не реже 1 раза в 3 года.

Сотрудники ОРЭИ БНЦ СО РАН предложили следующие цели деятельности Совета:

- осуществление комплексного анализа социально-экономической ситуации в Республике Бурятия;

- экспертизу проектов стратегических документов, определяющих социально-экономическое развитие республики, представляемых правительством республики;

- выработку вариантов государственной политики, направленной на формирование условий, обеспечивающих динамичное и устойчивое развитие экономики и социальной сферы региона, рост уровня и качества жизни населения.

В 2016 г. был принят закон «О стратегическом планировании в Республике Бурятия», заложивший правовые основы системы стратегического планирования в республике ${ }^{1}$. Основная дискуссия при обсуждении его проекта в Народном Хурале (законодательном органе Республики Бурятия) развернулась относительно порядка утверждения Стратегии, т. к. в федеральном законе существует альтернативные варианты: стратегия субъекта РФ может утверждаться законодательным органом либо высшим исполнительным органом. В итоге было принято решение о том, что Стратегия утверждается законом Республики Бурятия. Таким образом, предложение сотрудников ОРЭИ БНЦ СО РАН было поддержано депутатами Народного Хурала.

\footnotetext{
${ }^{1}$ О стратегическом планировании в Республике Бурятия: закон Республики Бурятия от 4 марта 2016 года № 1639-V.
} 
В целом республиканский закон практически полностью копирует соответствующие положения федерального закона. Его отличительной особенностью является включение дополнительного требования по содержанию Стратегии: «сбалансированное решение экологических и социально-экономических проблем на Байкальской природной территории».

В целях координации деятельности по обеспечению устойчивого социальноэкономического развития Республики Бурятия был создан консультативный орган - Совет при главе РБ по стратегическому планированию1. Предполагалось, что его деятельность будет направлена на подготовку предложений по основным направлениям социально-экономической политики Бурятии, определению стратегии и тактики ее реализации, механизмов, обеспечивающих устойчивое развитие экономики.

Развернулась дискуссия по вопросам разработки документов стратегического планирования в Республике Бурятия, включая Стратегию социальноэкономического развития. Сотрудниками ОРЭИ БНЦ СО РАН был предложен алгоритм разработки этих документов, включавший 5 этапов:

1. Подготовка проектов документов стратегического планирования СЭР Республики Бурятия.

2. Разработка предложений и рекомендаций по проектам документов.

3. Общественное обсуждение проектов документов в формате конференций, круглых столов, семинаров.

4. Корректировка документов стратегического планирования с учетом результатов обсуждения.

5. Принятие документов стратегического планирования.

В целях повышения качества подготовки Стратегии социальноэкономического развития Республики Бурятия предлагалось:

- предусмотреть публичное оглашение приоритетов, целей и задач социально-экономического развития Республики Бурятия в формате выступления главы Республики Бурятия, выступлений на общественных мероприятиях (коллегиях) руководителей исполнительных органов государственной власти Республики Бурятия;

- обеспечить привлечение научно-экспертных организаций для разработки проекта Стратегии;

- обеспечить проведение экспертизы проекта Стратегии;

- обеспечить общественное обсуждение проекта Стратегии в формате конференций, круглых столов, семинаров.

Для подготовки Стратегии было предложено привлечь организации, имеющие большой опыт разработки подобных документов и согласования их с федеральными органами исполнительной власти, включая известные экспертноаналитические центры, например, ИЭОПП СО РАН, ЗАО «Международный центр развития регионов».

\footnotetext{
${ }^{1}$ Об образовании Совета при Главе Республики Бурятия по стратегическому планированию и о внесении изменения в указ Главы Республики Бурятия от 07.11.2013 № 217 «О координационных и совещательных органах, образуемых Главой Республики Бурятия, Правительством Республики Бурятия, органами исполнительной власти Республики Бурятия»: указ главы Республики Бурятия от 28.08.2015 № 136.
} 
Наилучшим вариантом стало бы создание консорциума по разработке Стратегии, обеспечивавшего эффективное взаимодействие между участниками стратегического планирования. Как отмечает В. Селиверстов: «Успехи в региональном стратегировании... в существенной степени достигнуты благодаря включению механизма взаимодействия и сотрудничества... федеральных и региональных властей, бизнес-структур, учреждений Российской академии наук, институтов гражданского общества» [4].

В качестве участников стратегического планирования предлагалось привлечь крупные бизнес-структуры, определяющие будущее развитие экономики республики. Перспективные планы их развития, включая инвестиционные проекты, по мнению сотрудников ОРЭИ БНЦ СО РАН, необходимо согласовывать со Стратегией и соответствующими государственными программами.

На наш взгляд, руководству республики следовало бы учесть опыт разработки документов стратегического планирования других субъектов РФ. Можно и нужно было использовать наработки сибирских регионов, в которых упор делался на особенностях территории.

Так, в Новосибирской области с учетом важнейших конкурентных преимуществ научно-инновационных, инжиниринговых и производственных преимуществ региона была разработана «Программа реиндустриализации экономики Новосибирской области на период до 2025 г.» [5]. В Томской и Кемеровской областях в качестве стержневых элементов перспективного развития рассматривались ведущие отрасли экономики - соответственно нефтегазовый и угольный комплексы [6; 7].

При разработке региональных стратегий важно выявление точек и зон опережающего экономического роста, определение проблем и перспектив развития и расширения существующих городских агломераций, формирование кластеров [8]. На наш взгляд, необходимо выстраивать правильную «архитектуру» и алгоритм разработки Стратегии, включая «флагманские проекты», которые в перспективе стали бы локомотивом, движущей силой развития экономики Бурятии. В этой связи было бы логично использовать опыт ИЭОПП СО РАН по разработке документов стратегического планирования [9].

Вместе с тем правительство Республики Бурятия выбрало иной путь. Еще до принятия регионального закона о стратегическом планировании было принято решение о подготовке Стратегии социально-экономического развития Республики Бурятия до 2030 г. ${ }^{1}$. Был разработан «Примерный план мероприятий (дорожная карта) по определению приоритетов долгосрочного социальноэкономического развития Республики Бурятия», представлявший, по сути, план действий по разработке и утверждению Стратегии в течение октября 2015 г. декабря 2016 г.

На первых этапах разработки Стратегии проводились заседания 18 экспертных площадок (групп) по различным направлениям: от определения миссии и SWOT-анализа Республики Бурятия до взаимодействия с интернет-сообществом. Как заявил занимавший тогда пост главы Республики Бурятия В. В. Наговицын:

1 Об определении приоритетов долгосрочного социально-экономического развития Республики Бурятия: распоряжение главы Республики Бурятия от 14.10.2015 № 75-рг. 
«...на основе рабочих протоколов этих групп будет составляться конечный документ «Стратегии-2030». ${ }^{1}$ Сложилась парадоксальная и уникальная в негативном смысле ситуация, когда приоритеты перспективного развития Бурятии определяло не правительство, а некие эксперты, зачастую не имевшие опыта разработки документов стратегического планирования. Отметим, что разработчик и эксперт - это специалисты разного профиля².

Кроме того, размытой оказалась и ответственность за выработку приоритетов долгосрочного социально-экономического развития Республики Бурятия: наряду с куратором (руководителем исполнительного органа государственной власти РБ) в каждой экспертной площадке были определены руководители из числа экспертов. В этих условиях трудно было ожидать получение качественных и содержательных документов.

Одновременно с работой экспертных площадок был проведен конкурс на выполнение научно-исследовательской работы «Разработка проекта Концепции и проекта Стратегии социально-экономического развития Республики Бурятия на период до 2030 года». В нем могли участвовать любые организации, имевшие опыт выполнения работ сопоставимого характера. Разработку важнейшего документа, определяющего долговременные перспективы развития Бурятия, правительство республики, по сути, отдало на откуп случаю аналогично закупу канцелярских товаров! Следует согласиться с известным специалистом по региональному стратегическому планированию Б. Жихаревичем, отметившим вредность использования шаблонов госзакупок для творческих работ, каковой и является разработка стратегии развития региона [10].

В итоге конкурс выиграл Сибирский институт управления - филиал РАНХГиС, предложивший наименьшую цену контракта. Разработанный исполнителем проект Стратегии не соответствовал техническому заданию и характеризовался низким качеством:

1. Проект Стратегии характеризуется недостаточностью конкретных предложений и проектов.

2. Нечетко и размыто описаны приоритетные направления развития Республики Бурятия на долгосрочную перспективу.

3. Форма изложения материала далека от совершенства. Нет четкости, связанности и завершенности во многих предложениях текста.

4. В тексте очень много смысловых, грамматических и синтаксических ошибок, например, «Угроза сохранения историко-культурного наследия народов, проживающих в Бурятии», Северомуйский район и т. п.

Первоначальный вариант проекта Стратегии был исправлен. Скорректированный проект, несмотря на оставшиеся и очевидные недочеты, был не единогласно одобрен на заседании Совета при главе Республики Бурятия по стратегическому планированию 29 ноября 2016 г.

${ }^{1}$ Бурятия-2030. В республике формируют стратегию развития на ближайшие 15 лет [Электронный ресурc]. URL: https://www.infpol.ru/165795-buryatiya-2030-v-respublikeformiruyut-strategiyu-razvitiya-na-blizhayshie-15-let/ (дата обращения: 10.09.2019).

2 Эксперт - это специалист, дающий заключение при рассмотрении какого-нибудь вопроса; разработчик - это специалист, занимающийся разработкой схемы, механизма, аппаратуры (Толковый словарь Ожегова). 
Тем не менее в условиях политических разногласий между органами исполнительной и законодательной власти Республики Бурятия, вызванных непринятием Народным Хуралом отчета об исполнении закона Республики Бурятия «О Программе социально-экономического развития Республики Бурятия на 2011-2015 годы», проект Стратегии не был принят [11].

После отставки В. В. Наговицына, состоявшейся 7 февраля 2017 г., вопрос об утверждении «Стратегии социально-экономического развития Республики Бурятия до 2030 года» был снят с повестки дня Народного Хурала.

\section{Литература}

1. Иванов О. Б., Бухвальд Е. М. Стратегическое территориальное планирование в регионах России // ЭТАП: экономическая теория, анализ, практика. 2018. № 3. С. 7-21.

2. Жихаревич Б. С. Заметки по итогам XV форума стратегов (2016 г.) //Региональная экономика. Юг России. 2017. № 1(15). С. 13-24.

3. Климанов В. В., Будаева К. В., Чернышова Н. А. Направления регионального стратегирования и программирования в России // Региональные исследования. 2016. № 4(54). C. $17-30$.

4. Селиверстов В. Е. Стратегическое планирование и стратегические просчета: российские реалии и тенденции // Регион: Экономика и Социология. 2016. № 4(92). С. 6-46.

5. Кулешов В. В., Селиверстов В. Е. Программа реиндустриализации экономики Новосибирской области: идеология разработки и основные направления реализации // Регион: Экономика и Социология. 2015. № 3(87). С. 88-122.

6. Томская область: трудный выбор своего пути / под ред. В. В. Кулешова. Новосибирск: ИЭОПП СО РАН, 2014. 260 c.

7. Стратегия "Кузбасс-2035": в гармонии с углем / В. А. Крюков [и др.] //ЭКО. 2018. № 11(533). С. 8-30.

8. Климанов В. В., Будаева К. В. Точки роста как элемент стратегического планирования в регионах России // Региональные исследования. 2017. № 3(57). С. 99-106.

9. Селиверстов В. Е. Программа реиндустриализации экономики Новосибирской области: основные итоги разработки // Регион: Экономика и Социология. 2016. № 1(89). C. $108-134$.

10. Жихаревич Б. С. Рынок территориального стратегического консалтинга в России в 2016-2018 гг.: заметки инсайдера // Региональная экономика. Юг России. 2019. Т. 7, № 1. C. 4-17.

11. Дондоков 3. Б.-Д. О мониторинге реализации документов стратегического планирования Республики Бурятия // Вестник БНЦ СО РАН. 2016. № 4. С. 138-142.

\section{WORKING-OUT OF THE STRATEGY FOR DEVELOPMENT OF THE REPUBLIC OF BURYATIA UNTIL 2030: UNSEIZED OPPORTUNITIES AND GAPS}

Zorikto B.-D. Dondokov

Dr. Sci. (Econ.), Prof., Chief Researcher,

Buryat Scientific Center SB RAS

8 Sakhyanovoy St., Ulan-Ude 670000, Russia

Dorzhi Banzarov Buryat State University

24a Smolina St., Ulan-Ude 670000, Russia

E-mail: dzorikto@mail.ru 
Elena N. Vanchikova

Dr. Sci. (Econ.), Prof., Rro-Rector for Economics and Development, Dorzhi Banzarov Buryat State University

24a Smolina St., Ulan-Ude 670000, Russia

Chief Researcher,

Department of Regional Economic Research, Buryat Scientific Center SB RAS

8 Sakhyanovoy St., Ulan-Ude 670000, Russia

E-mail: evanch@mail.ru

The article discusses working out of the Strategy for Socio-Economic Development of the Republic of Buryatia until 2030. We have analyzed the proposals of the scientific community to the legislative and executive authorities of the republic on legislative drafting, creation of a mechanism for strategic budgeting in Buryatia, and the main provisions of the Council for Strategic Planning of Socio-Economic Development under the Head of the Republic of Buryatia. The speech of the Head of Buryatia has shown the importance of public announcing the priorities, goals and objectives of socio-economic development of the republic. There is a necessity of organizing the effective interaction between the participants of strategic planning. We have described the proposed algorithm for the development of strategic planning documents, and shown the advantages of attracting scientific and expert organizations and creation of a Consortium for the strategizing. The article reveals the gaps in the process of preparing a long-term development strategy by the government of the Republic of Buryatia, describes the draft strategy of developers and the reasons for its non-approval.

Keywords: strategic planning; region; socio-economic development; the Republic of Buryatia; laws and regulations; scientific organizations; long-term development priorities; expert forums; public debate; propolsals and recommendations; draft strategy. 